\title{
Advocacy: speaking on behalf of our patients
}

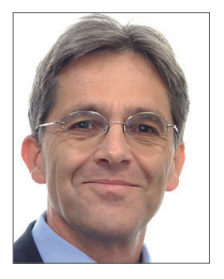

\author{
Andreas Baumbach*, MD, $\mathrm{PhD}$, President EAPCI \\ Queen Mary University London and Barts Heart Centre, London, United Kingdom
}

What role should a learned society play in advocacy? And what exactly can we do?

The mission of the European Society of Cardiology (ESC) is to "reduce the burden of cardiovascular disease". We aligned the mission of the European Association of Percutaneous Cardiovascular Interventions (EAPCI) to "reduce the burden of cardiovascular disease by percutaneous cardiovascular interventions". The most visible activities of the large EAPCI community are in the field of education and training: we all know the courses EuroPCR and PCR London Valves, which annually teach and train more than 15,000 participants locally and many more through online media. We have the EAPCI/PCR Fellows Course for the next generation of young interventional cardiologists. Less known are our activities in the field of advocacy.

We believe that, in parallel with the ESC Advocacy efforts, which have recently included lobby work for more funding of cardiovascular research from Brussels, there is a need to speak and act on behalf of our patients suffering from conditions that can be treated by interventional techniques. In this article I would like to highlight three major EAPCI initiatives of recent years.

The "For life" initiatives started with Stent for Life, the first EAPCI programme which aimed to bring guideline-recommended ST-elevation myocardial infarction (STEMI) treatment to countries and areas where there was little provision of primary $\mathrm{PCI}^{1}$. Country champions worked together with the steering group to assess practice and implement improvements, leading to increased access to life-saving treatments for patients suffering an acute myocardial infarction. The rest is history! The concept was very successful, and continues to spread, now as a global movement in collaboration with our partner PCR under the name "Stent - Save a Life!".

The same principle was applied when it became apparent that transcatheter aortic valve implantation (TAVI) showed a wide variation in availability across Europe to patients in need. The Valve for Life initiative was founded and successfully improved access to TAVI in the three pilot countries - Poland, France and Portugal ${ }^{2}$. We will be looking to engage a fourth country in 2020 and will report on the results of this successful programme.

Information about the penetration of treatment in individual regions and countries is essential. A comparison between countries gives an opportunity to argue for improvement and harmonisation and helps when lobbying for a better access and improved infrastructure; hence, the EAPCI White Book 2016 was created. In a unique survey, 16 countries in Europe contributed detailed numbers on healthcare resources with a focus on interventional cardiology, procedures and resources for percutaneous coronary interventions, and procedures and resources for structural heart interventions. The paper illustrates the still very large heterogeneity of numbers of procedures and access to life-saving treatments across our member countries. The second edition, now under the name EAPCI Atlas, is underway with increased capture of data. We will be able not only to spotlight activity and infrastructure every two years, but also, and importantly, to show dynamic developments in procedures, and their relationship to new evidence and guideline recommendations.

*Corresponding author: St Bartholomew's Hospital, West Smithfield, London, EC1A 7BE, United Kingdom.

E-mail:a.baumbach@qmul.ac.uk 
Finally, as the third example of EAPCI advocacy work, the new patient focus programme requires a mention. Launched in 2018, this initiative focuses on the direct interaction with our patients ${ }^{3}$. We have identified areas of need ${ }^{4}$ and started work on the involvement of patients in decision making, research, and, importantly, created useful tools for our practice. Led by Fina Mauri and Robert Byrne, we are developing Patient-Reported Outcome Measures (PROMS), Patient-Reported Experience Measures (PREMS), and a media-based tool to aid consent for coronary procedures. We expect to be able to present the results of these initiatives in early 2020 and look forward to their implementation in practice.

The work on advocacy will continue. We hope to attract support from you along the way and invite you to join in the efforts!

\section{References}

1. Widimsky P, Fajadet J, Danchin N, Wijns W. "Stent 4 Life" targeting PCI at all who will benefit the most. A joint project between EAPCI, Euro-PCR, EUCOMED and the ESC Working Group on Acute Cardiac Care. EuroIntervention. 2009;4:555-7.

2. Windecker S, Haude M, Baumbach A. Introducing a new EAPCI programme: the Valve for Life initiative. EuroIntervention. 2016;11:977-9.

3. Baumbach A. Patient Focus in Interventional Cardiology: the EAPCI Initiative. EuroIntervention. 2018;14:1087.

4. Barbato E, Mauri J, Byrne RA, Roffi M, Fitzsimons D, Toth G, Capodanno D, Mehilli J, Petronio AS, Chieffo A, Vardas P, Naber CK, Dudek D, Haude M, Baumbach A. Patient focus in interventional cardiology: proceedings of the 2018 summit of the European Association of Percutaneous Cardiovascular Interventions (EAPCI) - Nice, France, 20-21 June 2018. EuroIntervention. 2019;14:1720-3. 


\section{EAPCI}

European Association of

Percutaneous Cardiovascular

Interventions

Receiving an EAPCI grant helped me to advance in my career as interventional cardiologist. Few women choose to embrace this demanding but gratifying profession and I am glad that the EAPCI has decided to support women allocating $50 \%$ of its 2020 grants to them

\section{Dr. Giuliana Capretti EAPCI Grant winner 2017}
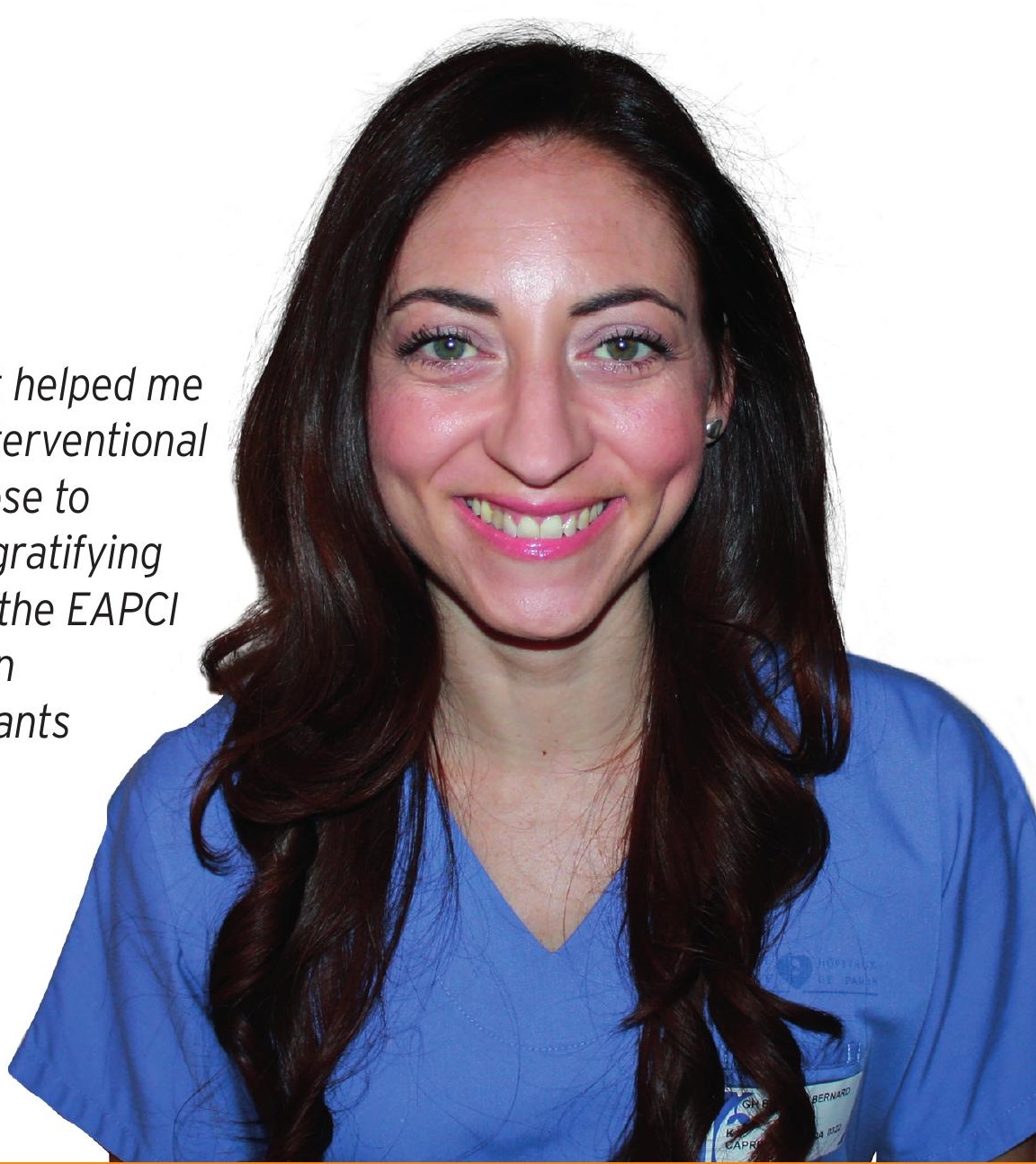

\section{$\triangle P$ PIY for an EAPCI Education \& Training Grant}

\section{- Application deadline: 15 January 2020}

